\title{
Canadian Orofacial Pain Team workshop report on the Global Year Against Orofacial Pain
}

\author{
Gilles J Lavigne DMD PhD RCDC(c), Barry J Sessle MDS PhD DSc(hc) FRSC FCAHS*
}

GJ Lavigne, BJ Sessle. Canadian orofacial pain team workshop report on the Global Year Against Orofacial Pain. Pain Res Manag 2015;20(1):7-14.

The year 2013-2014 has been designated the Global Year Against Orofacial Pain by the International Association for the Study of Pain. Accordingly, a multidisciplinary Canadian and international group of clinical, research and knowledge-transfer experts attended a workshop in Montreal, Quebec. The workshop had two aims: to identify new pathways for innovative diagnosis and management of chronic orofacial pain states; and to identify opportunities for further collaborative orofacial pain research and education in Canada.

Three topics related to chronic orofacial pain were explored: biomarkers and pain signatures for chronic orofacial pain; misuse of analgesic and opioid pain medications for managing chronic orofacial pain; and complementary alternative medicine, topical agents and the role of stress in chronic orofacial pain.

It was determined that further research is needed to: identify biomarkers of chronic orofacial post-traumatic neuropathic pain, with a focus on psychosocial, physiological and chemical-genetic factors; validate the short- and long-term safety (ie, no harm to health, and avoidance of misuse and addiction) of opioid use for two distinct conditions (acute and chronic orofacial pain, respectively); and promote the use of topical medications as an alternative treatment in dentistry, and further document the benefits and safety of complementary and alternative medicine, including stress management, in dentistry. It was proposed that burning mouth syndrome, a painful condition that is not uncommon and affects mainly postmenopausal women, should receive particular attention.

Key Words: Biomarkers; Complementary and alternative medicine; Opioid misuse; Orofacial pain; Pain; Topical analgesics

$\mathrm{T}$ he International Association for the Study of Pain has designated 2013-2014 as the Global Year Against Orofacial Pain; therefore, it was timely that the Canadian Orofacial Pain Team Workshop was held in Montreal (Quebec) on November 21 and 22, 2013. The workshop was sponsored by the Orofacial Pain Team Workshop, the Network for Canadian Oral Health Research, and the Institute of Musculoskeletal Health and Arthritis of the Canadian Institutes of Health Research. A multidisciplinary group of clinical, research and knowledge-transfer experts gathered from across Canada and abroad to pursue two aims: to identify new pathways for innovative diagnosis and management of chronic orofacial pain states; and to identify opportunities for further collaborative orofacial pain research and education in Canada.

Three main topics were presented, followed by panel discussions. The outcome was three sets of proposals for promising directions in chronic orofacial pain research, with the aim of improving the quality of life of orofacial pain patients through better diagnosis and management. Each set of proposals was presented to the full workshop so that overlapping opportunities could be identified and ideas for new research collaborations generated.

\section{Rapport de l'atelier de l'équipe canadienne sur la douleur orofaciale au sujet de l'année mondiale contre la douleur orofaciale}

L'Association nationale pour l'étude de la douleur a désigné 2013-2014 l'année mondiale contre la douleur orofaciale. Ainsi, un groupe multidisciplinaire canadien et international d'experts dans les secteurs de la clinique, de la recherche et du transfert du savoir a assisté à un atelier à Montréal, au Québec. Cet atelier avait deux objectifs : établir de nouvelles voies pour le diagnostic et la prise en charge novateurs des états de douleur orofaciale chronique et déterminer les occasions de recherche et de formation coopératives plus poussées sur la douleur orofaciale au Canada.

Le groupe a exploré trois sujets liés à la douleur orofaciale chronique : biomarqueurs et signatures de la douleur en cas de douleur orofaciale chronique, mauvais usage des analgésiques et des opioïdes contre la douleur afin de prendre en charge la douleur orofaciale chronique et médecine complémentaire et parallèle, agents topiques et rôle du stress dans la douleur orofaciale chronique.

Il a été établi que d'autres recherches s'imposent pour déterminer les biomarqueurs de la douleur orofaciale neuropathique post-traumatique chronique, en s'attardant sur les facteurs psychologiques, physiologiques et chimiques. Il faut également valider l'innocuité à court et à long terme (aucun danger pour la santé et évitement du mésusage et de la toxicomanie) des opioïdes dans deux états distincts (douleur orofaciale aiguë et chronique, respectivement). Enfin, il faut promouvoir l'utilisation des médicaments topiques comme autre traitement en dentisterie et attester des avantages et de l'innocuité des médicaments complémentaires et parallèles, y compris la gestion du stress, en dentisterie. On a proposé de porter une attention particulière à la stomatodynie, un trouble douloureux qui n'est pas rare et qui touche surtout les femmes postménopausées.

\section{TOPIC 1: BIOPSYCHOSOCIAL MARKERS AND PAIN}

SIGNATURES FOR CHRONIC OROFACIAL PAIN F Chouchou, T Dao, G Deluca-Canto, L Diatchenko, R Dubner, JP Goulet, N Huynh, G Lavigne, P Rainville, P Schweinhardt, Z Seltzer, P Svensson, A Velly

A number of issues were raised about the different types of chronic pain that can persist in the head, face and neck. First, there is currently no consensus on the types of chronic orofacial pain under the major pain classifications established by the American Academy of Orofacial Pain, the International Association for the Study of Pain and the International Headache Society. Different definitions and terminologies are used, and they are different with regard to their explanations of causes (etiology), descriptions of signs and symptoms, and diagnostic criteria. This reflects the lack of knowledge and the need for future studies along the lines of what was performed for temporomandibular disorders (TMD) in the recently updated Research Diagnostic Criteria for TMD $(1,2)$. Among the many types of orofacial pain, TMDs are the most common $(3,4)$. TMDs involve pain in the joint that connects the two jaw bones and muscles that move the jaw $(1,5)$. Second, although certain risk factors for chronic orofacial pain have been identified, the

\footnotetext{
*Workshop speakers and debate participants are listed as co-authors under each topic title Correspondence: Dr Gilles J Lavigne, Faculté de medecine dentaire, Universite de Montreal, CP 6128, Succ Centre ville, Montreal,

Quebec H3C 3J7. Telephone 514-343-6005, fax 514-343-2233, e-mail gilles.lavigne@umontreal.ca
}

OPEN ACCESS

This open-access article is distributed under the terms of the Creative Commons Attribution Non-Commercial License (CC BY-NC) (http:// creativecommons.org/licenses/by-nc/4.0/), which permits reuse, distribution and reproduction of the article, provided that the original work is properly cited and the reuse is restricted to noncommercial purposes. For commercial reuse, contact support@pulsus.com 
underlying mechanisms remain largely unclear. Third, chronic orofacial pain is frequently accompanied by comorbid pain conditions elsewhere in the body, as well as general health, psychosocial, sleep or motor disturbances, which complicate diagnosis and management. Fourth, reports of acute and chronic orofacial pain prevalence range widely, from $3 \%$ to $12 \%$. Fifth, pain per se is also difficult to quantify and is commonly only assessed by the patient's own subjective report. Sixth, there is insufficient evidence for the power of current approaches to predict patients' response to pain medications. Consequently, clinicians must prescribe pain medications based on their own experience or using trial and error.

On the other hand, several tests are now available to help assess orofacial pain. These include psychosocial questionnaires and psychophysiological tests such as qualitative sensory testing, which can be performed chairside, and quantitative sensory testing (QST), which is usually performed under experimental conditions but is applied in some clinics. QST approaches have been developed to test somatosensory functions such as heat and cold sensitivity, mechanical detection threshold, mechanical pain threshold, mechanical pain sensitivity, wind-up ratio, vibration detection threshold and pressure pain threshold. Both types of tools are considered to be reasonably reliable and sensitive, and are used to identify biomarkers of chronic orofacial pain, to help uncover the underlying mechanisms of pain, and to measure acute postoperative or chronic pain and response to treatment (6-9). Brain imaging is also a powerful tool to better understand sensory and emotional mechanisms of pain, the role of pain expectation on placebo analgesia and the endophenotype of pain $(10,11)$.

A biomarker is a naturally occurring molecule, gene or characteristic that can be used to identify and better understand a disease or disorder. Several biomarkers can be used to better understand pain in general and orofacial pain in particular. For example, electroencephalography (EEG) signals can be used to record the brain's electrical activity when pain occurs. They are particularly useful in surgery and postsurgical situations and for children, the elderly and patients who cannot communicate for any reason. However, some types of EEG signals correspond with patient-reported pain better than others. For example, EEG gamma oscillations have been proposed as potential pain biomarkers. They are also useful for predicting subjective pain intensity and for indicating pain experienced during the various states of consciousness, such as those associated with anesthesia, psychoactive medication and sleep (12-14). The pain-reward mechanism, placebos and sleep studies are research avenues that may help to better characterize pain biomarkers in relation to risk factors and comorbidities (15-18). Brain imaging methods include a number of proven biomarker approaches that can identify sensory and emotional responses to pain in specific brain structures. New imaging methods are being applied in both mechanistic and treatment efficacy studies (eg, sensory perception, placebo, medication and cognitive behavioural studies) (19-21). Major advancements have been made in understanding TMD pain. For example, medical history (ie, comorbidities) has been linked to sensation related to pain pressure tests as a clinical biomarker, and genes have been linked to psychosocial factors (22). The identification of genotype (DNA sequence) and epigenetic features (non-DNA changes that could have occurred over time and in interactions with behaviour) are paths to be further investigated; such research needs to be performed, given the complexity of pain and the considerable variability in its expression in pain patients, as recently reported by a group of experts in pain research and genetics $(10,23,24)$. Other promising biomarkers are being explored, including cytokines, which are essentially hormonal regulators that are released through a complex chain of neural events and that come into play during infections, immune responses, inflammation and trauma (25). Cytochromes, which are naturally occurring enzymes, are also biomarkers worth exploring.

Another conclusion of the first workshop session was that more collaborative work, rather than single-laboratory studies, is needed to identify promising biomarkers and phenotypes and assess associations with other factors such as stress, psychological and environmental influences, and the impact of comorbidities. In addition, better cytokine, genetic and, eventually, epigenetic testing methods are required to gain a deeper understanding of the neurological interactions as well as the role of motor and sleep function in the genesis and/or persistence of chronic orofacial pain. An exemplary model has been provided by the Oral Pain: Prospective Evaluation and Risk Assessment (OPPERA) project on TMD, a multicentre prospective clinical study launched by the United States National Institutes of Health to assess the role of psychosocial, clinical, psychophysiological and genetic variables $(22,26)$.

These various issues prompted a workshop panel discussion and led to the following research recommendations, with a focus on chronic neuropathic orofacial pain conditions such as burning mouth, posttraumatic or postsurgical pain and trigeminal neuralgia (intense facial pain due to nerve damage) (27-29).

\section{Panel 1: Research recommendations concerning biopsychosocial markers of chronic orofacial pain}

The workshop participants had identified the need for further studies on potential biomarkers, using questionnaires on health and mood, qualitative sensory testing and QST, as well as genetic markers to improve disease diagnosis and to measure changes in orofacial diseases and pain. The panel discussed these points and first considered that a useful biomarker should be variable in the population and it should show moderate heritability. This raised some critical questions about how to assess biomarkers for chronic orofacial pain: How can representative samples of individuals with chronic orofacial pain be obtained and tested? Which chronic orofacial pain conditions should be considered? Which chronic orofacial pain traits should be assessed? These basic questions need to be answered before chronic orofacial pain can be properly studied and treated.

Further issues concern the appropriate phenotypes (genetically based characteristics and traits that interact with the environment) to examine, such as endophenotypes, which are intermediate phenotypes. To date, there is no consensus on the most informative phenotypes to consider. Uncertainty regarding the risk factors (eg, social, cultural, psychological, genetic, epigenetic) and mechanisms involved in chronic orofacial pain was mentioned.

Of the neuropathic orofacial pain conditions, research into posttraumatic neuropathic pain (PTNP) appears to be one of the most promising directions, as described below in the recommended research directions (30-32).

There is a wealth of phenomic and genetic data available, much of it generated by animal studies, but more information is needed to fully understand the dynamics of chronic neuropathic orofacial pain. For instance, although pain sensitivity varies among individuals, it is known that TMD is associated with different types of psychological stress. Association gene studies can identify how genetic makeup (in terms of architecture, locus, pathways and targets) is associated with pain and its characteristics.

The panel proposed the following specific recommendations:

- Develop a prospective study in a new cohort of patients who have sustained orofacial trauma, and follow these patients to identify those who transition to chronic PTNP.

- Administer psychological, personality, clinical and psychophysical tests to patients in this proposed study, also taking into consideration cultural differences among these patients.

- Collect saliva and blood to extract genomic DNA, non-nucleotide markers (epigenetic changes over time), peptides and protein expression, etc, as potential markers of the main pain outcomes and endophenotypes for PTNP. Inclusion of inflammation-immune biomarkers is also necessary.

- Conduct brain imaging experiments in a subset of the patients to assess the biological and emotional dimensions of pain.

- Data collection from a cross-Canada cohort is expected to last between three and five years.

- Study animal models of PTNP to identify analogous biomarkers and underlying mechanisms of PTNP. 


\section{TOPIC 2: MISUSE OF ANALGESIC WITH A FOCUS ON OPIOID PAIN MEDICATIONS FOR MANAGING CHRONIC OROFACIAL PAIN}

B Cairns, K Craig, JP Goulet, A Kolta, D Lam, G Lavigne, M Lynch, J O'Keefe, S Potvin, N Rei, A Samaha, E Whitney

For years, clinicians have expressed concern about prescribing opioids due to the risks of misuse, abuse and addiction. However, orofacial pain cannot be managed without such risks (33). Recently, clinicians, the media and politicians are taking this concern more seriously (34). In Ontario alone, from 2006 to 2008, 58\% of drug-related deaths $(n=1,359)$ were associated with opioids (35). This is a highly sensitive issue for Canadian clinicians who are managing acute and chronic pain. They must balance the risks against the patient's rights, expectations of pain relief and effectiveness of the treatment $(36,37)$.

But how serious is the opioid problem? According to the Canadian Alcohol and Other Drug Use Monitoring Survey, one in five (19\%) Canadians with chronic pain reported using opioids, and $4.8 \%$ of these acknowledged nonmedical prescription opioid use (NMPOU) $(38,39)$. NMPOU refers to the use of opioids by individuals who acknowledge using pain relievers more than they were instructed to, obtaining a pain reliever from family or friend, or from any source without a prescription (ie, diversion of prescribed medication), or using a pain reliever to get high. Nevertheless, the single leading reason for using opioids in $>50 \%$ of individuals who engage in NMPOU appears to be pain relief $(39,40)$. This raises a crucial question: are we managing pain with the most effective medications and tools?

Opioids are used medically to obtain relief from intense pain and to avoid the consequences of pain on daily functioning, mood changes and suicidal ideation. These are risks that need to be weighed against the risks of misuse and addiction. Currently, $8 \%$ of fibromyalgia patients are reported to be at risk for suicide, and this risk is five times higher in chronic pain patients with a history of illicit drug use $(41,42)$.

As the number of opioid prescriptions rises, opioid addiction and misuse rates are rising in parallel $(34,43)$. Although clear guidelines are available for opioid use to manage chronic noncancer pain (http:// nationalpaincentre.mcmaster.ca/opioid/), the problem remains critical, and we need to reconsider our approach $(37,44)$. First, the workshop participants were concerned about the fact that patients with chronic pain and who use opioids regularly are frequently stigmatized as addicts. For most, this is the only way to obtain pain relief and maintain a minimal quality of life. It is, therefore, critical to understand the difference between legitimate use and dependence or addiction. Physical dependence is normal and temporary, although it is associated with withdrawal. Addiction, on the other hand, is a primary neuropsychiatric disorder involving compulsive, uncontrolled drug-seeking and drug-taking behaviours. Opioids may also trigger a dopamine-related reward process in the brain, changes that appear to be very long-lived $(45,46)$. The net effect is a reward-based synaptic process in the brain that influences and possibly alters many cognitive functions, including learning, memory, judgment, prediction, reward and motivation processes $(47,48)$. The pursuit of natural rewards may turn into a compulsive pursuit of drugs, which is what clinicians want to prevent.

Mental health status and the risk for opioid misuse or addiction are critical issues that must be considered before prescribing opioids for chronic use $(44,49,50)$. Interestingly, patients with schizophrenia do not appear to suffer from chronic pain as much as the rest of the population. They feel the pain, but do not appear to care. This may be due to alterations in their pain-processing mechanisms resulting from a change in the complex interplay between the brain's excitatory and inhibitory systems. Schizophrenics can exhibit higher dopamine activity, which makes them less sensitive to nociceptive pain (typically the acute pain resulting from injury, infection or inflammation) $(51,52)$. However, the safety of opioid use by patients with mental health problems remains a challenging issue $(44,49)$.

Sometimes regular use of any type of analgesic, including opioids, will actually worsen the problem. Headaches may progress from occasional to regular, and constipation is an unpleasant adverse effect.
Furthermore, regular opioid use may also trigger hyperalgesia in some susceptible individuals: they become more sensitive to pain or feel pain more intensely. Hyperalgesia is a complex physiological reaction that may lead to requests for higher doses, known as opioid overuse pain syndrome. These individuals should be taken off the medication for an appropriate length of time $(53,54)$.

The long-term benefits and safety of opioid use for chronic noncancer pain remains an open issue (34). Moreover, only $15 \%$ to $25 \%$ of patients significantly benefit from opioids after three years of regular use (55). According to the opioid guidelines for long-term use for noncancer pain, patients should be $>30$ years of age and experiencing moderate to severe pain that compromises their functioning. They should be capable of using the medication in the prescribed manner. Furthermore, they should be unable to take other effective medications, for whatever reason (37).

When is it appropriate to prescribe opiates for chronic orofacial pain, and how should medication use be monitored? Again, the major medical organizations have not reached a consensus on guidelines for specific and safe treatments without the risks of misuse or addiction. The Canadian Guidelines for Safe and Effective Use of Opioids for Chronic Non-Cancer Pain and more recent concerns were highlighted during the workshop $(36,37,44,56)$. The recommendations include taking a thorough patient history and screening for potential misuse. Medication effectiveness should be monitored and informed consent for treatment obtained. Work-related risks may also need to be assessed, eg, for commercial drivers and pilots (57). Morphine equivalent doses $>200 \mathrm{mg}$ per day appear to be associated with an increased risk for death if abused and, thus, this dose is recommended as the upper limit for treatment of chronic noncancer pain. Furthermore, because morphine and other opioid analgesics may also exacerbate breathing disturbances during sleep in vulnerable patients, the lowest possible dose is recommended in these patients $(58,59)$. Elderly patients should be tapered off benzodiazepines because the combination of opioid analgesics and benzodiazepines is likely to cause excessive sedation and breathing disturbances in this population. Initial opioid doses should be small, and different opioids should be tried to find the best one. In 1986, the WHO suggested a stepwise approach, also known as the analgesic pain pyramid (60). Effectiveness, adverse events and aberrant behaviour should be noted. The medication may need to be given in another dose, switched to another type or terminated. If medications appear to be misused, patients can be prescribed methadone or buprenorphine, or given limited prescriptions and patient education with monitoring approaches can be used to minimize drug abuse and resale (diversion). Urine testing is the most effective monitoring method, but the use of such tests is controversial due to Canadian ethics and confidentially issues (56).

Use of tamper-resistant formulations is an approach to prevent misuse/abuse of opioids under study by governmental agencies in Canada. However, more research is needed to confirm its effectiveness for daily use by patients, and other strategies need to be developed in parallel to prevent abusers from switching to other drugs such as heroin (61-63). The obligation to protect the population against drug misuse and abuse has to be balanced with the human right of patients experiencing severe chronic pain to obtain pain relief (64).

Dentists who prescribe opioids to chronic orofacial pain patients to manage acute or chronic pain must also become involved in preventing opioid misuse and addiction (33):

- To manage acute pain, the lowest-risk drugs should be prescribed first (eg, nonsteroidal anti-inflammatory analgesics such as acetylsalicylic acid, acetaminophen or ibubrofen). Opioid drugs should be prescribed only for severe or chronic pain after all other alternatives have been tried (eg, cognitive behavioural therapy, antiepileptic medications such as pregabalin, or antidepressive medications such as amitriptyline or duloxetine). The analgesic pain pyramid paradigm needs to be taught and promoted in clinical practice $(60)$.

- Clinicians should prescribe the minimum number of pills needed to manage the pain, and include a renewable option. After oral surgery, between 10 and 40 doses are being prescribed, with a mean of 20 . 
Generally, a considerable proportion of prescribed pain pills are leftovers, and we do not know what patients do with them $(33,65)$.

- By reducing the number of prescribed pills, including a repeat prescription option when permissible and getting pharmacists more involved in renewal procedures, the risk of leftover pills can be reduced. Leftover pills are a major cause of misuse and distraction (use of medications for purposes other than pain relief) (33). Pharmacists are key partners in managing repeat prescriptions. For instance, they can limit the number of pills over the first few days to help prevent the risks associated with leftovers. They could also offer return of unused medication to the pharmacy for proper destruction. Clinicians who prescribe opioids should be aware that they need to be available to answer pharmacists' questions. Otherwise, the safety chain to prevent misuse is broken (66).

Screening patients for their risk of opioid misuse, abuse or addiction according to the Canadian and United States guidelines can dramatically reduce opioid misuse $(37,44,56)$. Clinicians should also be alert for certain behaviours exhibited by their patients, such as 'doctor shopping', frequently lost prescriptions, repeated requests for prescriptions, stealing or borrowing drugs, forging prescriptions or resisting changes to their medication even when there are adverse side effects. Identified predictors of misuse are a history of taking multiple substances, psychiatric disorders, alcohol or cocaine abuse, a family history of substance abuse, young age, criminal past, high-risk environment, social and/or employment problems, thrill-seeking behaviour, heavy smoking, and severe depression or anxiety. Which individuals are least at risk? They include older, generally compliant, stable, thoughtful, responsible and easy-going types.

Among the proposed assessment strategies are patients' self-report clinical questionnaires and interviews, and clinicians' checklists. However, the most effective strategy is a urine test, if the patient agrees (see the Guidelines, http://nationalpaincentre.mcmaster.ca/ opioid/). Patients should be monitored regularly, and some provinces and states have prescription monitoring programs to help with this. It is important to keep in mind that only a small percentage of chronic pain patients will misuse or become addicted to opioid pain medications. As mentioned above, clinicians should be trained in the choice of pain medication, dosages, number of pills, reduction of leftover pills and follow-up methods. They should inform their patients about alternative pain management methods, the need to avoid giving pills to family members or friends, to not mix drugs with alcohol and to avoid using other medications not recommended by the clinician, including illegal drugs. These approaches are instrumental for preventing misuse and eventual addiction $(56,67)$.

When investigating or treating pain, we should not overlook social and psychological aspects. Pain is the result of complex interactions among many factors, including individual biology, the personal experience of pain and environmental influences. Pain and opioid analgesic addiction cannot be considered outside of this vast biopsychosocial context. Besides treating individual patients with empathy and awareness, dentists and physicians should not be ruled by either opiophilia or opiophobia.

Participants in the workshop panel discussed all of these issues and proposed recommendations for future research, as presented below.

\section{Panel 2: Research recommendations related to opioid misuse for managing chronic orofacial pain}

The panel discussed the workshop presentations and identified some key issues that remain to be clarified.

- It is unclear how often Canadian family dentists prescribe opioid analgesics to treat moderate to severe chronic orofacial pain.

- There is little evidence to support the use of opioid analgesics in chronic orofacial pain.

- The use of opioid analgesics for chronic orofacial pain that has not responded adequately to all other treatments may be considered, but only for the subgroup of patients with persistent orofacial pain who have not responded to other surgical, pharmacological or psychological approaches (eg, post-traumatic pain, postsurgical or endodontic pain and, more rarely, musculoskeletal pain).
- The decrease in opioid efficacy and safety over time as well as the risk for sleep breathing abnormalities in susceptible patients also remain critical issues to consider.

The panel developed the following specific recommendations:

- Conduct prospective studies to assess the best and safest management of acute orofacial pain to prevent chronic pain.

- Include in such studies measures of pain, including brain imaging and genetic biomarkers, as well as psychosocial risk factors for misuse and addiction.

- Include measures over six-month periods to determine the prevalence of persistent postoperative pain and post-traumatic pain and the relationship to chronic opioid use.

- Test screening algorithms, prevention protocols (lowest dose and number of pills; prescription renewal to avoid unused opioid pills), and education programs for clinicians and patients in terms of their effectiveness in dental practice and their impacts on the risk of misuse and addiction.

\section{TOPIC 3: COMPLEMENTARY AND ALTERNATIVE MEDICINE, TOPICAL AGENTS AND THE ROLE OF STRESS IN CHRONIC OROFACIAL PAIN}

L Avivi-Arber, K Blanchard, N Rei, J Sawynok, P Schweinhardt, B Sessle, P Svensson, V Singh, N Thie, M Ware, A Woda

Patients use complementary alternative medicine (CAM) for both 'push' and 'pull' reasons. Push reasons include dissatisfaction with conventional medicine due to side effects, long waiting lists, ineffective treatments and lack of time. People may also reject science and technology in general, or the so-called 'establishment', or they may be desperate because they are not being listened to or are not obtaining the expected pain relief. Pull reasons include a belief in the safety and effectiveness of natural, holistic, noninvasive treatments that are in line with their personal philosophy. Patients also believed that they have active control over their treatment, and they can spend more time with practitioners. Treatments range from traditional Chinese medicine and meditation to biofeedback, physical therapy, massage, chiropractic therapy, acupuncture and electric fields, to name only a few. In general, they are 'lower-tech' and higher-touch than conventional treatments. CAM content is barely present in the dental education curriculum. This is not surprising because CAM is rarely taught in clinical medicine $(68,69)$.

Not all CAM approaches are without risks, however. Natural products, such as tea tree oil and black willow bark, are used to treat pain, but they come with certain safety issues, such as potential drugherb interactions and lack of standardization. The use of an evidencebased approach is mandatory in all health disciplines and, in recent years, CAM research has made significant progress in providing more information on efficacy and safety, partly due to more open-minded government attitudes (http://nccam.nih.gov). In addition, some patients who use CAM may not seek conventional medical help for more serious conditions that require diagnosis and more aggressive medical treatment (eg, oncology). Patients should be made to understand that they need to report their use of CAM because some treatments may have negative interactions with pharmacological agents (eg, those used for anxiety and in oncology) $(70,71)$. It should also be mandatory for studies investigating CAMs to report any adverse effects, a condition that is rarely met but is becoming more standard $(72,73)$. Although CAM is frequently used to treat general chronic pain, there is only limited evidence for its effectiveness in treating most types of chronic orofacial pain (74).

In the case of acupuncture, there is an ongoing debate regarding whether acupuncture really 'works' (ie, the endogenous analgesic systems are activated) or whether patients feel better because of the 'needling effect'. In other words, acupuncture analgesia may involve a type of active placebo effect, as occurs in other therapeutic treatments and in relation to the patient's beliefs (75). There is some evidence supporting the use of acupuncture for managing TMD pain (76). 
TABLE 1

Suggested directions for future national and international collaborative research in chronic orofacial pain

- $\quad$ Develop collaborations among major pain associations

- Reach a consensus on classification (taxonomy) and harmonization with newer international research diagnostic criteria

- Establish standard diagnostic tests

- Integrate brain, genetic and immune biomarker research findings and technological advances within a more comprehensive diagnostic approach

- $\quad$ Conduct interdisciplinary longitudinal studies to assess behavioural, psychological, societal, environmental, epigenetic (non-DNA changes) and genetic (DNA changes) risk factors and disease progression

- Conduct prospective studies and develop evidence-based and tailored treatments for medical, dental and complementary and alternative medicine applications and practice

- Initiate comparative effectiveness studies (ie, real-world settings) versus classical efficacy randomized clinical trials (ie, too often conducted in overly controlled or selective conditions for regulatory agency needs)

- Establish reliable treatment efficacy and efficiency outcomes by using valid monitoring tests

- Use animal models to identify chronic orofacial pain biomarkers and complimentary alternative medicine mechanisms

- Set clear guidelines or best practices guidance, in collaboration with professional organizations and government agencies, on opioid use for safe chronic orofacial pain management (dose, number of pills, unused pill risk)

- $\quad$ Partner with health professional colleges, governmental agencies, pharmacists and family physicians to develop strategies to prevent opioid misuse and abuse

- $\quad$ Promote the use of evidence-based complementary and alternative medicine approaches to chronic orofacial pain management

- Develop a strategic communication plan to update clinicians and educate the public on the best and safest treatments for chronic orofacial pain

Traditional Qigong is an ancient Chinese practice involving movements, postures, breathing exercises and meditation. It has been reported to significantly and sustainably improve a wide range of conditions, including chronic orofacial pain, food allergies, asthma, sleep disorders, carpel tunnel syndrome and migraines, among others. It appears to be more effective when practiced regularly; thus, highly motivated individuals would benefit most from it (77). However, rigorous trials combining quantitative and qualitative approaches are needed to provide hard evidence on the benefits and the best approaches for delivery $(73,78,79)$.

Biofeedback, which involves the use of electrical stimulation to inhibit muscle activity, appears to have a positive effect on sleep bruxism (tooth grinding) and some chronic pain conditions (TMD, headache, fibromyalgia); however, paradoxically, it does not appear to significantly reduce pain intensity $(80)$. It has been suggested that a combination of biofeedback and cognitive behavioural therapy would be more effective (81). More information is needed through long-term follow-up studies involving larger patient samples.

Some CAM procedures may also relieve pain by reducing stress. It is known that chronic orofacial pain as well as many other conditions, such as chronic fatigue syndrome and fibromyalgia, are stress-related (stress was also identified as a possible biomarker of chronic orofacial pain in topic 1) (82). Abnormal or sustained exposure to stress causes an abnormal response to stress, such that the stress system is in a state of permanent failure. Instead of the normal short-alarm reaction to daily stresses, which sends extra oxygen and glucose to the body so it can cope with emergencies, fibromyalgia patients experience a 'longer' type of stress response in which they fail to receive that 'extra fuel'. These patients may first need to perform more endurance exercise (ie, low-intensity, long-duration exercise) and progressively add resistance exercise (ie, short duration of repeated, more intense effort), to reeducate their stress response system (A Woda, unpublished observations). Pain management exercise programs provide a promising treatment avenue, if performed safely. Although there is little supporting evidence - and the little that is available is considered to be low quality - this avenue merits further investigation (83-85).

Recently, an alternative to conventional medication routes has been introduced, namely the use of topical agents such as ointments, mouth rinses, powders and sprays for orofacial pain conditions (86, 87). They are applied as local anesthetics, antidepressants, anticonvulsants, anti-inflammatories and more. They have no or only minimal side effects and they generally do not interact with other drugs. They are particularly beneficial for patients who cannot ingest certain medications and will certainly be useful in an aging population. For the most effective treatment, it is important to find a pharmacist who can properly compound the agent. Burning mouth syndrome was proposed to be sufficiently prevalent as to merit further study, and topical clonazepam was mentioned as a treatment that is not widely known to many practitioners yet may be useful for a number of patients. Promising avenues to pursue include the use of topical agents to relieve burning mouth pain and other types of neuropathic orofacial pain. Agents such as clonidine (an alternative to clonazepam, with a safer addiction profile) could be investigated through randomized controlled trials $(88,89)$.

Participants in the workshop panel discussed all of these issues and proposed recommendations for future research, as outlined below.

Panel 3: Research recommendations related to CAM, topical agents and the role of stress in chronic orofacial pain

The first research direction proposed by the panel was to clarify the difference between CAM and the use of topicals (ie, topical analgesics). The point was raised that they form an unlikely pair because CAM involves untested and unaccepted therapies, whereas topical agents are pharmaceuticals, with a different delivery system. It was decided that they should be considered as independent entities for the purposes of chronic orofacial pain management because they appear to act through different mechanisms and because topical agents fall into the category of standardized pharmacotherapeutic interventions.

Burning mouth syndrome and neuropathic orofacial pain were identified as common disorders that are, nevertheless, rarely encountered by general practitioners treating chronic orofacial pain. In addition, and even when referred to a specialized practitioner, the management strategies developed to date to help these patients are often ineffective. The panel proposed the following research recommendations:

- Establish awareness and education groups, with an emphasis on reviewing the current knowledge and formulating guidelines to assist clinicians in decision making with respect to burning mouth syndrome.

- Develop a multicentre study of treatments for burning mouth syndrome (eg, capsaicin and lidocaine compared with clonidine versus placebo rinse). Thus, capsaicin-lidocaine treatment could be investigated parallel to clonidine treatment.

- Use larger samples in efficacy or effectiveness trials to assess the benefits and risks of CAM and the use of topical medications as alternatives to systemic medication.

- Conduct CAM studies using animal models of chronic orofacial pain to better understand the mechanisms of action of CAM, and promote translational research to enhance CAM acceptance for treatment of pain and associated factors such as mood alterations, sleep disturbances and stress-response disturbances for improvements in quality of life. 


\section{MAIN CONCLUSIONS AND FUTURE DIRECTIONS FOR CHRONIC OROFACIAL PAIN RESEARCH AND MANAGEMENT}

Because almost 20\% of Canadians experience chronic pain and $8 \%$ have chronic orofacial pain, these patients need help to prevent psychological and societal dysfunction. In addition, medication misuse is a recognized problem in Canada that may lead to addiction and suicide. It was clear to the workshop participants of the need to devote greater attention to chronic orofacial pain to improve the quality of life of chronic orofacial pain patients.

It was also clear from the workshop discussions and recommendations that more research is needed to identify biomarkers of chronic orofacial pain (as revealed through the use of approaches such as brain imaging and genetic characterization), and to clarify societal, cultural and environmental interactions, using analyses of large population data sets.

Furthermore, it was recommended to develop pharmacological, psychological-behavioural and CAM treatments and to monitor their long-term efficacy and safety, and determine the underlying mechanisms in animal and human experimental models.

More comprehensive and overarching explorations (multidisciplinary approaches) are needed to obtain a more complete picture of what happens when pain occurs or persists (Table 1 ).

\section{REFERENCES}

1. Peck CC, Goulet JP, Lobbezoo F, et al. Expanding the taxonomy of the diagnostic criteria for temporomandibular disorders. J Oral Rehabil 2014;41:2-23.

2. Schiffman E, Ohrbach R, Truelove E, et al. Diagnostic Criteria for Temporomandibular Disorders (DC/TMD) for Clinical and Research Applications: Recommendations of the International RDC/TMD Consortium Network* and Orofacial Pain Special Interest Groupdagger. J Oral Facial Pain Headache 2014;28:6-27.

3. Goulet JP, Lavigne GJ, Lund JP. Jaw pain prevalence among French-speaking Canadians in Quebec and related symptoms of temporomandibular disorders. J Dental Res 1995;74:1738-44.

4. Locker D, Slade G. Prevalence of symptoms associated with temporomandibular disorders in a Canadian population. Community Dent Oral Epidemiol 1988;16:310-3.

5. de Leeuw RaK, Gary D, eds. Orofacial Pain: Guidelines for Assessment, Diagnosis, and Management, 5th edn. Hanover Park: Quintessence Publishing, 2013.

6. Greenspan JD, Slade GD, Bair E, et al. Pain sensitivity and autonomic factors associated with development of TMD: The OPPERA prospective cohort study. J Pain 2013;14(12 Suppl):T63-74 e1-6.

7. Baad-Hansen L, Pigg M, Ivanovic SE, et al. Chairside intraoral qualitative somatosensory testing: Reliability and comparison between patients with atypical odontalgia and healthy controls. J Orofac Pain 2013;27:165-70.

8. Ettlin DA, Hitz T, Ramel C, et al. Quantitative sensory testing of intraoral open wounds. Int J Oral Maxillofac Surg 2013;42:401-5.

9. Yang G, Baad-Hansen L, Wang K, Xie QF, Svensson P. A study on variability of quantitative sensory testing in healthy participants and painful temporomandibular disorder patients. Somatosens Mot Res 2014;31:62-71.

10. Tracey I. Can neuroimaging studies identify pain endophenotypes in humans? Nat Rev Neurol 2011;7:173-81.

11. Tracey I. Getting the pain you expect: Mechanisms of placebo, nocebo and reappraisal effects in humans. Nat Med 2010;16:1277-83.

12. Zhang ZG, Hu L, Hung YS, Mouraux A, Iannetti GD. Gamma-band oscillations in the primary somatosensory cortex a direct and obligatory correlate of subjective pain intensity. J Neurosci 2012;32:7429-38.

13. Nilsson M, Piasco A, Nissen TD, et al. Reproducibility of psychophysics and electroencephalography during offset analgesia. Eur J Pain 2014;18:824-34.

14. Khoury S, Chouchou F, Amzica F, et al. Rapid EEG activity during sleep dominates in mild traumatic brain injury patients with acute pain. J Neurotrauma 2013;30:633-41.

15. Schweinhardt P, Seminowicz DA, Jaeger E, Duncan GH, Bushnell MC. The anatomy of the mesolimbic reward system: A link between personality and the placebo analgesic response. J Neurosci 2009;29:4882-7.
OTHER PARTICIPANTS AT THE WORKSHOP: C Arbour, P Arcache, S Khoury, S Marshansky, D Rizzo, S Tremblay.

ACKNOWLEDGEMENTS: The workshop was supported by the Network for Canadian Oral Health Research - Institute of Musculoskeletal Health and Arthritis of the Canadian Institutes of Health Research, with the collaboration of the Quebec Pain Research Network and the Network for Oral Health and Bone Research of the Fonds de recherche $d u$ Québec - Santé, the Canadian Research Chair Program, and the Association of Canadian Faculties of Dentistry. The authors thank three special invitees for their participation: $\mathrm{H}$ El-Gabalawy, Director of the Institute of Musculoskeletal Health and Arthritis - CIHR; D Matthews, Director of the Network for Canadian Oral Health Research; and J O'Keefe, Editor of the Journal of the Canadian Dental Association. The authors also thank M McKyes for editing this workshop summary. The skills of C Manzini and MP Roy in planning and running the workshop were greatly appreciated by all.

DISCLOSURES: No commercial funding was received for the workshop or report preparation.

16. Sanders AE, Essick GK, Fillingim R, et al. Sleep apnea symptoms and risk of temporomandibular disorder: OPPERA cohort. J Dental Res 2013;92(7 Suppl):70S-7S.

17. Laverdure-Dupont D, Rainville P, Montplaisir J, Lavigne G. Changes in rapid eye movement sleep associated with placeboinduced expectations and analgesia. J Neurosci 2009;29:11745-52.

18. Svensson P, Baad-Hansen L, Arima T. Association of orofacial pain conditions and sleep disturbance. In: Lavigne GJ, Cistulli PA, Smith MT, eds. Sleep Medicine for Dentists: A Practical Overview. Hanover Park: Quintessence Publishing, 2009:167-74.

19. Tracey I, Johns E. The pain matrix: Reloaded or reborn as we image tonic pain using arterial spin labelling. Pain 2010;148:359-60.

20. Schweinhardt P, Bushnell MC. Neuroimaging of pain: Insights into normal and pathological pain mechanisms. Neurosci Lett 2012;520:129-30.

21. Schweinhardt P, Bushnell MC. Pain imaging in health and disease how far have we come? J Clin Invest 2010;120:3788-97.

22. Slade GD, Fillingim RB, Sanders AE, et al. Summary of findings from the OPPERA prospective cohort study of incidence of first-onset temporomandibular disorder: Implications and future directions. J Pain 2013;14(12 Suppl):T116-24.

23. Mogil JS. Pain genetics: Past, present and future. Trends Genet 2012;28:258-66.

24. Lotsch J, Doehring A, Mogil JS, Arndt T, Geisslinger G, Ultsch A. Functional genomics of pain in analgesic drug development and therapy. Pharmacol Therapeut 2013;139:60-70.

25. Basi DL, Velly AM, Schiffman EL, et al. Human temporomandibular joint and myofascial pain biochemical profiles: A case-control study. J Oral Rehabil 2012;39:326-37.

26. Fillingim RB, Slade GD, Diatchenko L, et al. Summary of findings from the OPPERA baseline case-control study: Implications and future directions. J Pain 2011;12(11 Suppl):T102-7.

27. Iwata K, Imamura Y, Honda K, Shinoda M. Physiological mechanisms of neuropathic pain: The orofacial region. Int Rev Neurobiol 2011;97:227-50.

28. Klasser GD, Epstein JB. Oral burning and burning mouth syndrome. J Am Dent Assoc 2012;143:1317-9.

29. Klasser GD, Gremillion HA. Neuropathic orofacial pain patients in need of dental care. J Can Dent Assoc 2012;78:c83.

30. Parsons B, Schaefer C, Mann R, et al. Economic and humanistic burden of post-trauma and post-surgical neuropathic pain among adults in the United States. J Pain Res 2013;6:459-69.

31. Elias LA, Yilmaz Z, Smith JG, et al. PainDETECT: A suitable screening tool for neuropathic pain in patients with painful post-traumatic trigeminal nerve injuries? Int J Oral Maxillofac Surg 2014;43:120-6.

32. Smith JG, Elias LA, Yilmaz Z, et al. The psychosocial and affective burden of posttraumatic neuropathy following injuries to the trigeminal nerve. J Orofac Pain 2013;27:293-303. 
33. Denisco RC, Kenna GA, O'Neil MG, et al. Prevention of prescription opioid abuse: The role of the dentist. J Am Dent Assoc 2011;142:800-10.

34. Sullivan MD, Howe CQ. Opioid therapy for chronic pain in the United States: Promises and perils. Pain 2013;154(Suppl 1):S94-100.

35. Madadi P, Hildebrandt D, Lauwers AE, Koren G. Characteristics of opioid-users whose death was related to opioid-toxicity: A population-based study in Ontario, Canada. PLoS One 2013;8:e60600.

36. Boulanger A, Clark AJ, Squire P, Cui E, Horbay GL. Chronic pain in Canada: Have we improved our management of chronic noncancer pain? Pain Res Manag 2007;12:39-47.

37. Kahan M, Mailis-Gagnon A, Wilson L, Srivastava A; National Opioid Use Guideline Group. Canadian guideline for safe and effective use of opioids for chronic noncancer pain: Clinical summary for family physicians. Part 1: General population. Can Fam Physician 2011;57:1257-66, e407-18.

38. Lynch M. Nonmedical use of prescription opioids: What is the real problem? Pain Res Manag 2013;18:67-8.

39. Shield KD, Jones W, Rehm J, Fischer B. Use and nonmedical use of prescription opioid analgesics in the general population of Canada and correlations with dispensing levels in 2009. Pain Res Manag 2013;18:69-74

40. Lusted A, Roerecke M, Goldner E, Rehm J, Fischer B. Prevalence of pain among nonmedical prescription opioid users in substance use treatment populations: Systematic review and meta-analyses. Pain Physician 2013;16:E671-84.

41. Calandre EP, Navajas-Rojas MA, Ballesteros J, Garcia-Carrillo J, Garcia-Leiva JM, Rico-Villademoros F. Suicidal ideation in patients with fibromyalgia: A cross-sectional study. Pain Pract 2014 January 17. [Epub ahead of print]

42. Racine M, Choiniere M, Nielson WR. Predictors of suicidal ideation in chronic pain patients: An exploratory study. Clin J Pain 2014;30:371-8.

43. Manchikanti L, Helm S 2nd, Fellows B, et al. Opioid epidemic in the United States. Pain Physician 2012;15(3 Suppl):ES9-38.

44. Kahan M, Wilson L, Mailis-Gagnon A, Srivastava A; National Opioid Use Guideline Group. Canadian guideline for safe and effective use of opioids for chronic noncancer pain: Clinical summary for family physicians. Part 2: Special populations. Can Fam Physician 2011;57:1269-76, e419-28.

45. Hyman SE, Malenka RC, Nestler EJ. Neural mechanisms of addiction: The role of reward-related learning and memory. Ann Rev Neurosci 2006;29:565-98.

46. Garland EL, Froeliger B, Zeidan F, Partin K, Howard MO. The downward spiral of chronic pain, prescription opioid misuse, and addiction: Cognitive, affective, and neuropsychopharmacologic pathways. Neurosci Biobehav Rev 2013;37(10 Pt 2):2597-607.

47. Becker S, Gandhi W, Elfassy NM, Schweinhardt P. The role of dopamine in the perceptual modulation of nociceptive stimuli by monetary wins or losses. Eur J Neurosci 2013 July 10 [Epub ahead of print].

48. Gandhi W, Becker S, Schweinhardt P. Pain increases motivational drive to obtain reward, but does not affect associated hedonic responses: A behavioural study in healthy volunteers. Eur J Pain 2013;17:1093-103.

49. Fischer B, Lusted A, Roerecke M, Taylor B, Rehm J. The prevalence of mental health and pain symptoms in general population samples reporting nonmedical use of prescription opioids: A systematic review and meta-analysis. J Pain 2012;13:1029-44.

50. Mailis-Gagnon A, Lakha SF, Ou T, et al. Chronic noncancer pain: Characteristics of patients prescribed opioids by community physicians and referred to a tertiary pain clinic. Can Fam Physician 2011;57:e97-105.

51. Samaha AN. Can antipsychotic treatment contribute to drug addiction in schizophrenia? Prog Neuropsychopharmacol Biol Psychiatry 2014;52:9-16

52. Levesque M, Potvin S, Marchand S, et al. Pain perception in schizophrenia: Evidence of a specific pain response profile. Pain Med 2012;13:1571-9.

53. Raffa RB, Pergolizzi JV Jr. Multi-mechanistic analgesia for opioid-induced hyperalgesia. J Clin Pharm Ther 2012;37:125-7.

54. Mehendale AW, Goldman MP, Mehendale RP. Opioid overuse pain syndrome (OOPS): The story of opioids, Prometheus unbound. J Opioid Manage 2013;9:421-38.
55. Kissin I. Long-term opioid treatment of chronic nonmalignant pain: Unproven efficacy and neglected safety? J Pain Res 2013;6:513-29.

56. Chou R, Fanciullo GJ, Fine PG, et al. Clinical guidelines for the use of chronic opioid therapy in chronic noncancer pain. J Pain 2009;10:113-30.

57. Gomes T, Redelmeier DA, Juurlink DN, Dhalla IA, Camacho X, Mamdani MM. Opioid dose and risk of road trauma in Canada: A population-based study. JAMA Intern Med 2013;173:196-201.

58. Gomes T, Mamdani MM, Dhalla IA, Paterson JM, Juurlink DN. Opioid dose and drug-related mortality in patients with nonmalignant pain. Arch Intern Med 2011;171:686-91.

59. Jungquist CR, Flannery M, Perlis ML, Grace JT. Relationship of chronic pain and opioid use with respiratory disturbance during sleep. Pain Manag Nurs 2012;13:70-9.

60. Raffa RB, Pergolizzi JV Jr. A modern analgesics pain 'pyramid'. J Clin Pharm Ther 2014;39:4-6.

61. Cicero TJ, Ellis MS, Surratt HL. Effect of abuse-deterrent formulation of OxyContin. N Engl J Med 2012;367:187-9.

62. Coplan PM, Kale H, Sandstrom L, Landau C, Chilcoat HD. Changes in oxycodone and heroin exposures in the National Poison Data System after introduction of extended-release oxycodone with abuse-deterrent characteristics. Pharmacoepidemiol Drug Saf 2013;22:1274-82.

63. Severtson SG, Bartelson BB, Davis JM, et al. Reduced abuse, therapeutic errors, and diversion following reformulation of extended-release oxycodone in 2010. J Pain 2013;14:1122-30

64. Atkinson TJ, Schatman ME, Fudin J. The damage done by the war on opioids: The pendulum has swung too far. J Pain Res 2014;7:265-8.

65. Mutlu I, Abubaker AO, Laskin DM. Narcotic prescribing habits and other methods of pain control by oral and maxillofacial surgeons after impacted third molar removal. J Oral Maxillofac Surg 2013;71:1500-3.

66. Kahan M, Wilson L, Wenghofer EF, et al. Pharmacists' experiences with dispensing opioids: Provincial survey. Can Fam Physician 2011;57:e448-54.

67. Morley-Forster PK, Pergolizzi JV, Taylor R Jr, Axford-Gatley RA, Sellers EM. Mitigating the risk of opioid abuse through a balanced undergraduate pain medicine curriculum. J Pain Res 2013;6:791-801.

68. Spector ML, Fischer M, Dawson DV, et al. Complementary and alternative medicine usage by patients of a dental school clinic. Spec Care Dentist 2012;32:177-83.

69. Spector ML, Kummet CM, Holmes DC. Complementary and alternative medicine in predoctoral dental curricula: An exploratory survey of U.S. dental schools. J Dent Educ 2013;77:1610-5.

70. McLay JS, Stewart D, George J, Rore C, Heys SD. Complementary and alternative medicines use by Scottish women with breast cancer. What, why and the potential for drug interactions? Eur J Clin Pharmacol 2012;68:811-9.

71. Mooiman KD, Maas-Bakker RF, Hendrikx JJ, et al. The effect of complementary and alternative medicines on CYP3A4-mediated metabolism of three different substrates: 7-benzyloxy-4trifluoromethyl-coumarin, midazolam and docetaxel. J Pharm Pharmacol 2014;66:865-74.

72. Chen W, Zhang Y, Li X, Yang G, Liu JP. Chinese herbal medicine for diabetic peripheral neuropathy. Cochrane Database Syst Rev 2013;(10):CD007796.

73. Fischer FH, Lewith G, Witt CM, et al. High prevalence but limited evidence in complementary and alternative medicine: Guidelines for future research. BMC Complement Altern Med 2014;14:46.

74. Myers CD, White BA, Heft MW. A review of complementary and alternative medicine use for treating chronic facial pain. J Am Dent Assoc 2002;133:1189-96; quiz 259-60.

75. Kerr CE, Shaw JR, Conboy LA, Kelley JM, Jacobson E, Kaptchuk TJ. Placebo acupuncture as a form of ritual touch healing: A neurophenomenological model. Conscious Cogn 2011;20:784-91.

76. Ritenbaugh C, Hammerschlag R, Dworkin SF, et al. Comparative effectiveness of traditional Chinese medicine and psychosocial care in the treatment of temporomandibular disorders-associated chronic facial pain. J Pain 2012;13:1075-89.

77. Lynch M, Sawynok J, Hiew C, Marcon D. A randomized controlled trial of qigong for fibromyalgia. Arthritis Res Ther 2012;14:R178.

78. Sawynok J, Hiew C, Marcon D. Chaoyi Fanhuan Qigong and fibromyalgia: Methodological issues and two case reports. J Altern Complement Med 2013;19:383-6.

79. Sawynok J, Lynch M, Marcon D. Extension trial of qigong for fibromyalgia: A quantitative and qualitative study. Evid Based Complement Alternat Med 2013;2013:726062. 
80. Conti PC, Stuginski-Barbosa J, Bonjardim LR, Soares S, Svensson P. Contingent electrical stimulation inhibits jaw muscle activity during sleep but not pain intensity or masticatory muscle pressure pain threshold in self-reported bruxers: A pilot study. Oral Surg Oral Med Oral Pathol Oral Radiol 2014;117:45-52.

81. Shedden Mora MC, Weber D, Neff A, Rief W. Biofeedback-based cognitive-behavioral treatment compared with occlusal splint for temporomandibular disorder: A randomized controlled trial. Clin J Pain 2013;29:1057-65.

82. Woda A, L'Heveder G, Ouchchane L, Bodere C. Effect of experimental stress in 2 different pain conditions affecting the facial muscles. J Pain 2013;14:455-66.

83. Latorre PA, Santos MA, Heredia-Jimenez JM, et al. Effect of a 24-week physical training programme (in water and on land) on pain, functional capacity, body composition and quality of life in women with fibromyalgia. Clin Exp Rheumatol 2013;31(6 Suppl 79):S72-80.

84. Busch AJ, Webber SC, Brachaniec M, et al. Exercise therapy for fibromyalgia. Curr Pain Headache Rep 2011;15:358-67.
85. Busch AJ, Webber SC, Richards RS, et al. Resistance exercise training for fibromyalgia. Cochrane Database Syst Rev 2013;(12):CD010884.

86. Gremeau-Richard C, Woda A, Navez ML, et al. Topical clonazepam in stomatodynia: A randomised placebo-controlled study. Pain 2004;108:51-7.

87. Senye M, Mir CF, Morton S, Thie NM. Topical nonsteroidal anti-inflammatory medications for treatment of temporomandibular joint degenerative pain: A systematic review. J Orofac Pain 2012;26:26-32.

88. Sawynok J. Topical analgesics for neuropathic pain: Preclinical exploration, clinical validation, future development. Eur J Pain 2014;18:465-81.

89. Sawynok J. Topical analgesics in neuropathic pain. Current Pharm Des 2005;11:2995-3004. 


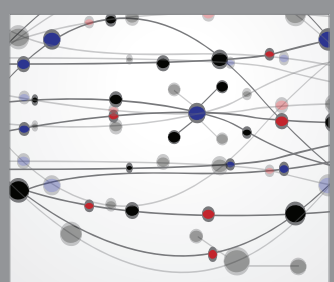

The Scientific World Journal
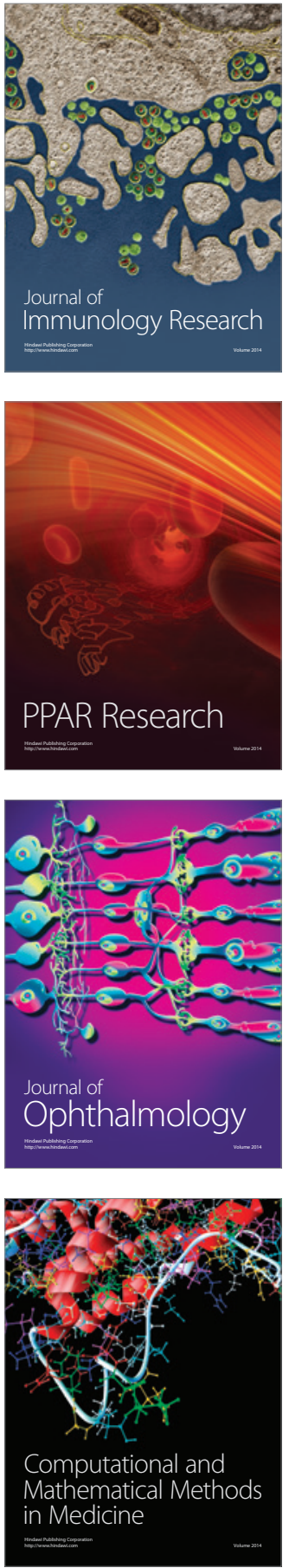

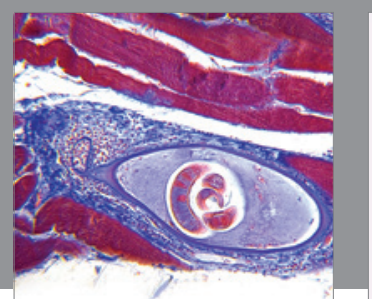

Gastroenterology Research and Practice

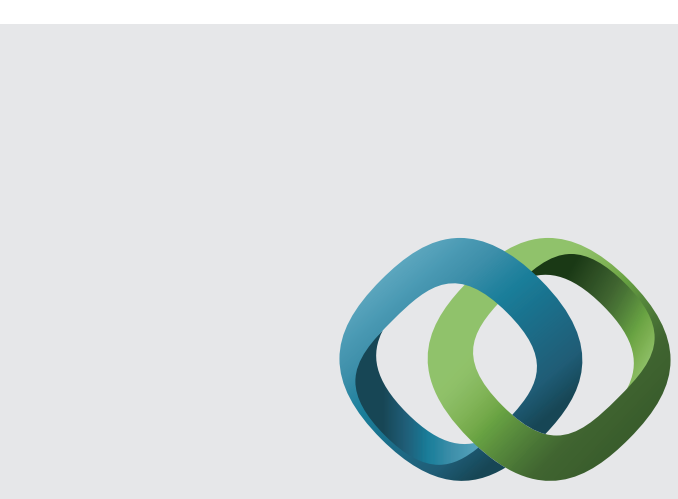

\section{Hindawi}

Submit your manuscripts at

http://www.hindawi.com
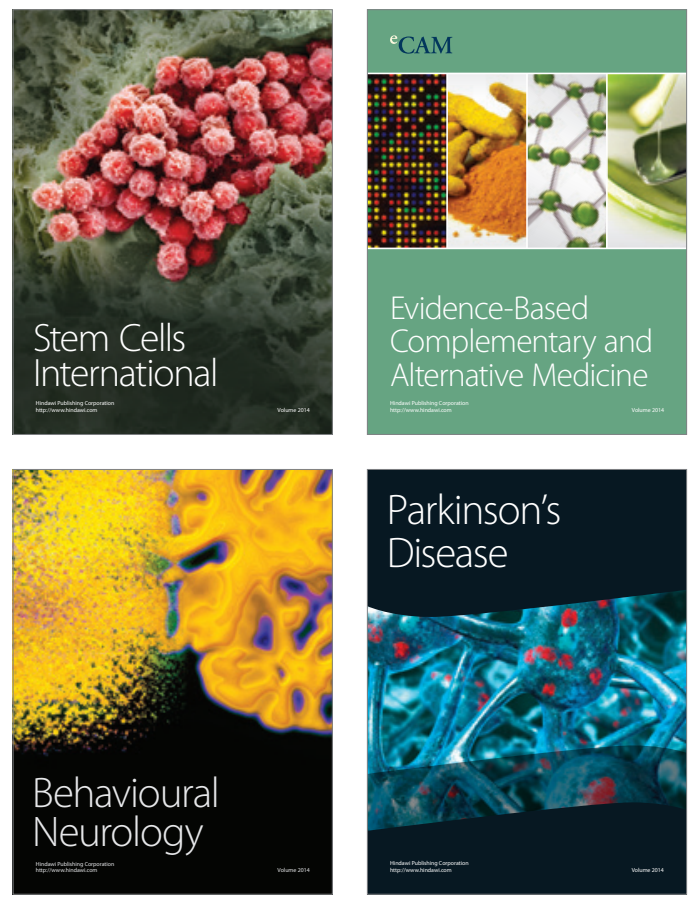
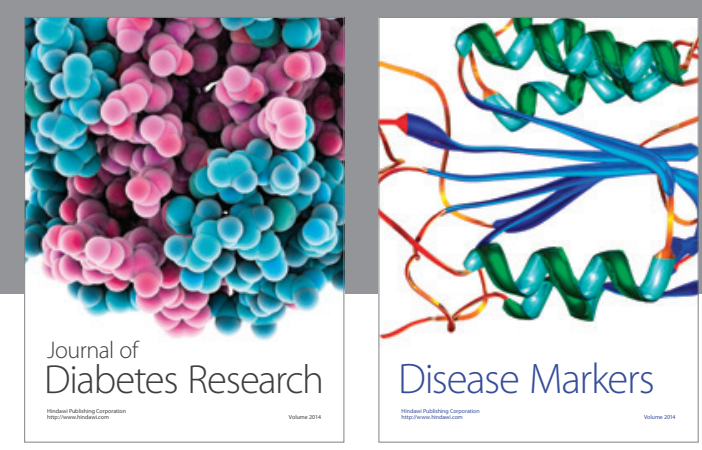

Disease Markers
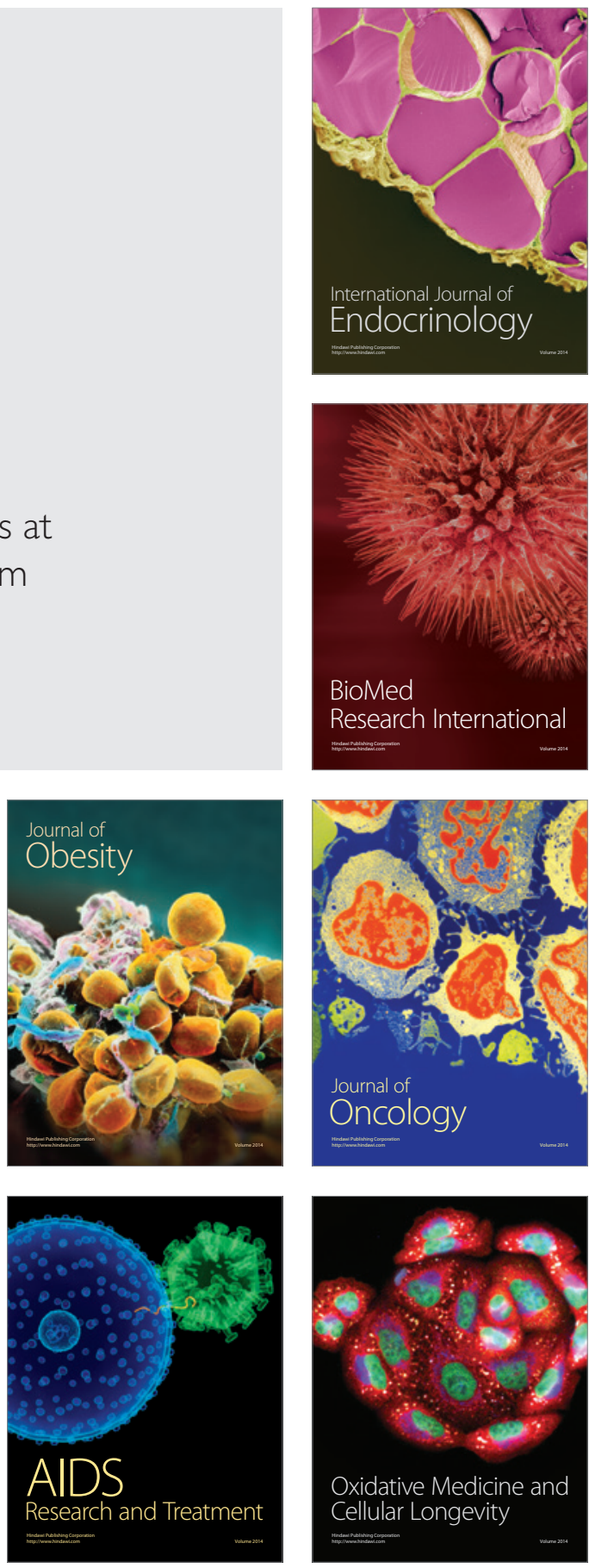